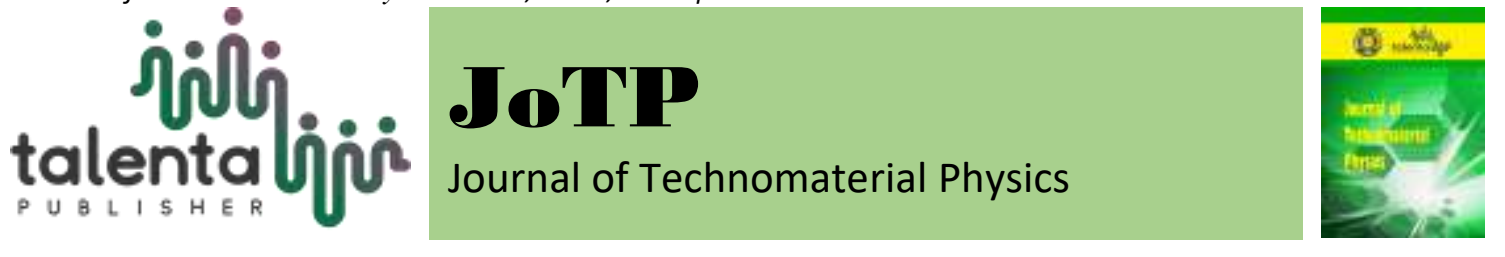

\title{
ST37 Steel Carburization with Coconut Charcoal
}

\section{Melya Dyanasari Sebayang *}

Department of Mechanical Enginering, Faculty of Engineering, Universitas Kristen Indonesia, Jl.Mayjen Sutoyo No. 1 Cawang-Jakarta Timur, Indonesia

\begin{abstract}
The carburization process is a surface hardening process where carbon is added to the surface without changing the core properties of the material. This process is carried out at the austenite temperature so that the carbon can diffuse into the phase. This process can only be done on low carbon steels with content below $0.25 \%$. This research was conducted on ST37 steel, which is steel with low carbon content with $0.18 \%$ carbon content. This type of steel is surface hardened with a carburizing temperature of $850 \mathrm{C}$ with a long lasting time of 1 hour, then it is carried out under moderate cooling with outside air media. And change its mechanical properties from the comparison of the initial mechanical properties of the specimen. The highest hardness value occurs in the carburizing process of coconut shell charcoal, but this hardness value occurs not because of the carburization process but because of the enlarged grain size caused by heating at temperatures below $723^{\circ}$ $\mathrm{C}$, thus reducing the elongation properties of the material. Carburizing with battery stone media is more efficient than coconut shell charcoal at temperatures below $723 \mathrm{C}$. Because the temperature is below the austenite temperature, the absorbed carbons cannot diffuse as happened in the carburization process, but the absorbed carbons can bind the grain boundaries and change their hardness by $4 \%$. In the microstructure research that occurs in this process nothing can change its phase because the temperature does not reach the austenite temperature. However, there are differences in the microstructure between the carburization process with coconut shell charcoal media.
\end{abstract}

Keyword: carburizing process, ST37 steel, coconut shell charcoal

Received 5 February 2021 | Revised [19 February 2021] | Accepted [25 February 2021]

\section{Introduction}

In developing countries, the development of metal and metal materials is very important and absolute to be applied and continues to be pursued in Indonesia as a developing country to produce a lot of these materials [1-3]. However, the existing tablespoons are not sufficient in terms of knowledge. ST37 steel is a low carbon steel with a carbon content of $\leq 0.25 \%$. This steel has mechanical properties that are low hardness but high ductility and are easy to shape [48]. Therefore this type of steel is widely used for construction, machining frames, bolts and others. However, this type of steel cannot be hardened except by hardening, one of which is by carburizing [9-11].

\footnotetext{
*Corresponding author at: Jl.Mayjen Sutoyo No. 1 Cawang-Jakarta Timur, Indonesia

E-mail address: melcan_sebayang@yahoo.co.id
} 
The human need for metal materials is increasing and the demand is very high, because metal materials are widely used for the needs of the automotive industry such as gears, chains and other machine components [12]. Therefore, humans are required to be more creative and innovative in metal development. As an answer to the demands of the market who want quality metal products so that the use of these metal component products can last a long time [13]. In the use of metal components often experience things that are not desired, such as cracks that cause breakage, or wear which causes relatively short component life. To overcome this, a heat treatment process is needed. Heat treatment basically consists of several stages, starting from heating to a certain temperature, holding for a while, and continuing at a certain speed. The process of heat treatment of steel components was done by diffusing chemical elements on the surface. One of the heat treatment processes that can be carried out is the carburization process in which the specimen is heated and the carbon content is added so that its mechanical properties can be changed [14]. In this process the carbon element is added only in the outer layer so that hardness is obtained on the surface of the carburized specimen.

This research aims are to find out the parameters of the heat resistance time of coconut shell carburization and battery stone to the surface hardness of ST37 steel, seeing the effect of carburization on the hardness value to be obtained, obtain the relationship between hardness and microstructure [15].

\section{Methods}

\subsection{Research Flowchart}

The research flowchart is given in Figure 1.

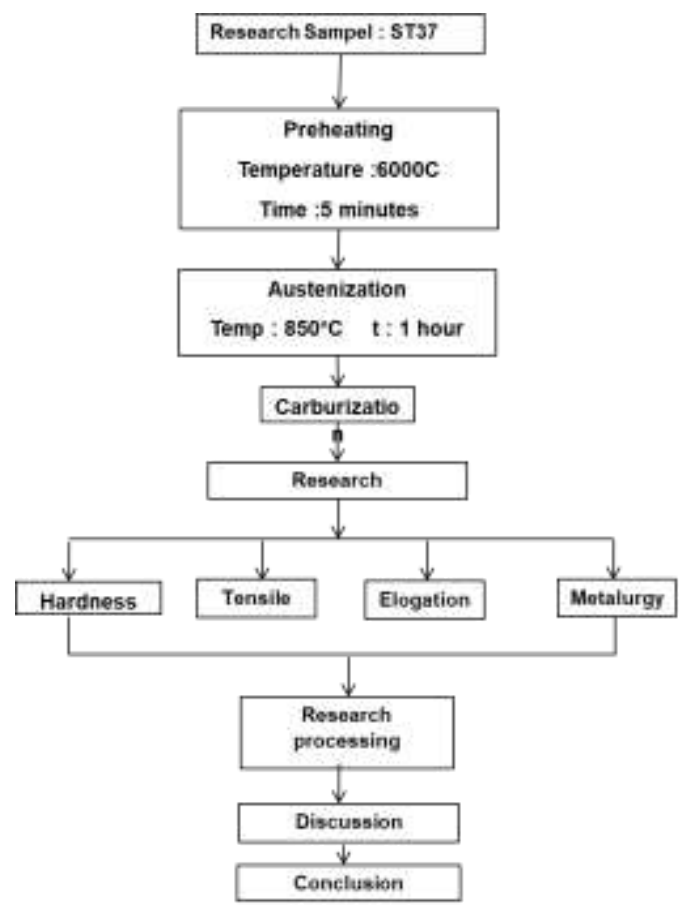

Figure 1. The research flowchart 


\subsection{Hardness methods}

The purpose of hardness testing is to determine the mechanical properties of the hardness of the specimen being tested, so there are three specimens to be tested, namely; Initial specimen ST37, ST37 carburized with coconut shell charcoal.

\subsection{Tensile Methods}

Tensile testing is carried out to assess the tensile strength, upstream strength, and elongation [16]. The specimen to be tested is installed in a tensile testing machine where the two ends of the specimen are clamped to be pulled with the same tensile load in both directions of the specimen to be tested.

\subsection{Elogations Methods}

The tensile strength test is performed using a tensile testing machine with a maximum capacity of 30,000 kgf. For each variation, the test is carried out 4 times so because there are 3 variations, there are 12 specimens for the tensile test.

\subsection{Microstructure Methods}

Micro-testing is carried out to observe the microstructure after the carburization process for varying holding time variables, the microstructure testing tool is carried out on the cross-section of the test object. The test object is cut perpendicular to the surface undergoing the heat treatment process using a hacksaw. Cooling water is applied during cutting to prevent changes in the structure of the sample. The test object that has been cut is then mounted with resin and the specimen is prepared, namely starting with sanding from coarse to fine. Then, the sample was polished with a velvet cloth which is given toothpaste as a smoother agent [17]. The polished specimen is then etched. After the above process is complete, a photo shoot is carried out using SEM (Scaning Electron Microscope)[18-20].

\section{Result and Discussion}

Solid carburization heat treatment process carried out on ST37 steel material with a long lasting time of 1 hour. After that the specimens were cooled with air media or (Normalizing). Then the specimen will be tested so that the analyzed data can be obtained so that mechanical properties and microstructure can be obtained that are different from the original properties of the specimen before carburizing.

\subsection{Hardness Analysis}

The carburizing process can affect the hardness values of the steel. It can be seen from the graph above that the highest hardness is in the carburization process with coconut shell charcoal. This testing process occurs trouble in the heating kitchen where the test should be done above the austenite temperature. Because the heating chamber cannot reach the austenite temperature, 
there is a failure of the carburizing process in coconut shell charcoal because the carbon from coconut shell charcoal is difficult to decompose into steel at low temperatures or below austenite.

Changes in the mechanical properties of hardness that occur in the carburization process with coconut shell charcoal are not due to the effect of carburization, but because of changes in grain size which cause changes in the mechanical properties of the carburized specimens in coconut shell charcoal. The hardness value increases because the grain size increases, which in the carburizing process the specimen is heated at a temperature below austenite with a charcoal size of 4-8 $\mathrm{mm}$ and a holding time of 1 hour, the carbon from the charcoal becomes difficult to decompose so that no carbon melts into the steel.

However, from the microstructure observation, there is less carbon that melts into the steel, because the grain size is finer so it doesn't take long to convert to $\mathrm{CO}_{2}$ gas which then reacts with $\mathrm{C}$ to become $\mathrm{CO}_{2}+\mathrm{C} \rightarrow 2 \mathrm{CO}$. With a higher temperature the equilibrium of the reaction tends to be to the right the more $\mathrm{CO}$. where the $\mathrm{C}$ formed is a carbon atom (carbon nascent) which actively diffuses into the austenite phase of the steel when the steel is heated. However, because the temperature cannot reach the austenite, the dissolved carbon on the surface cannot enter into the phase or change the phase, so that the dissolved carbon only binds to the grain boundaries so that the mechanical properties of its hardness increase $4 \%$ from the initial specimen.

\subsection{Tensile Analysis}

The effect of the carburization process on the value of tensile strength is explained. In the initial material the tensile strength value with a value of $425.22 \mathrm{~N} / \mathrm{mm}^{2}$, an increase in the material by carburizing process with coconut shell charcoal $18 \%$ against the initial specimen value with a value of $502.705 \mathrm{~N} / \mathrm{mm}^{2}$. The increase in tensile strength in the carburizing process of coconut shell charcoal occurs because the enlargement of the grain is not due to carbon diffusion into the steel so that it reduces the elongation properties of carburized steel with coconut shell charcoal which is due to the kitchen temperature not reaching austenite.

\subsection{Elogation Point Analysis}

The elongation value will be high if the strength of the specimen is low in the carburization process of coconut shell charcoal, the elongation value drops to $22 \%$ from the initial specimen.

\subsection{Microstructure Analysis}

In the carburizing process is to add carbon content to the surface of the steel so that it can change the phase to pearlite on the steel surface, but due to trouble in the heating 
kitchen so that the desired temprature is not achieved. So that the phase change cannot occur, this is because carbon cannot diffuse with the atoms in the phase content. From the microstructure of the carburization process with coconut shell charcoal media, the phase does not change, but changes actually occur in the grain size so that it affects the mechanical properties of the specimen. Meanwhile, in the carburizing process with coconut shell charcoal, the phase remains unchanged as the initial specimen

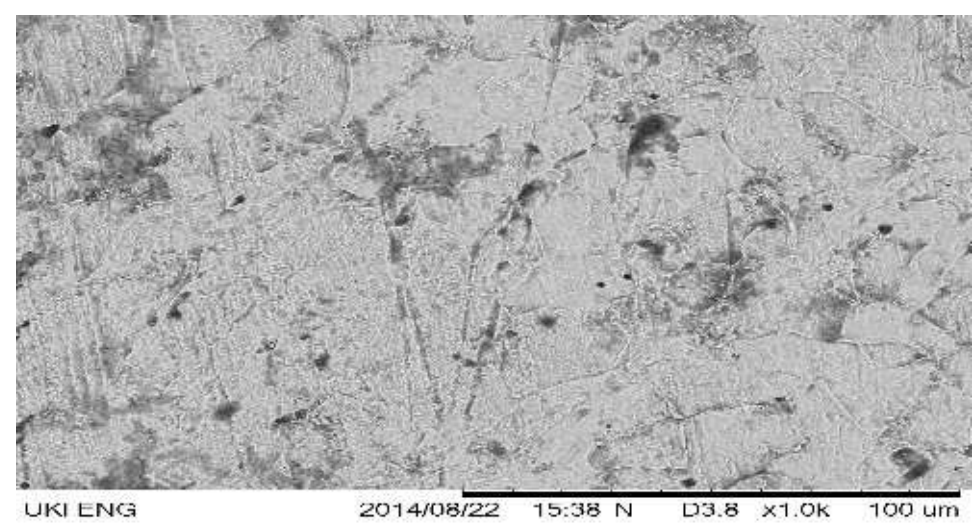

Figure 2. ST37 steel microstructure with magnfication of 1000 times

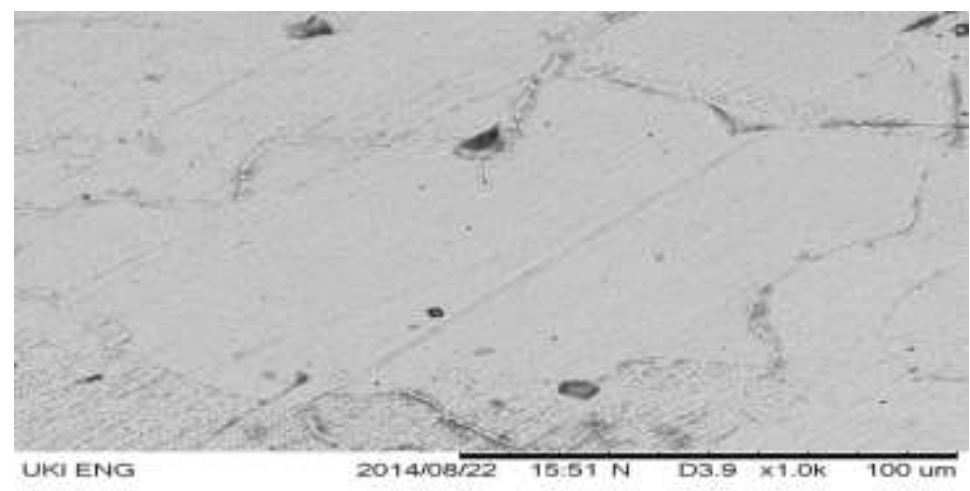

Figure 3. Microstructure of ST37 steel carburized coconut shell charcoal with magnification of 1000 times

\section{Conclusion}

Based on the results of the analysis obtained from the results of research on the carburization value of coconut shell charcoal media on the mechanical properties of low carbon steel ST 37, the following conclusions can be drawn:

a. The highest hardness value occurs in the carburizing process of coconut shell charcoal, but this hardness value occurs not because of the carburization process but because of the enlarged grain size caused by heating at temperatures below $723^{\circ} \mathrm{C}$, thus reducing the elongation properties of the material. The carburization process which was originally the goal of this study could not be achieved because there was damage to the 
heating kitchen at the time of this study so that the carbon which was expected to seep into the surface of the steel could not diffuse into the phase.

b. In the microstructure research that occurs in this process nothing can change its phase because the temperature does not reach the austenite temperature. but there are differences in the micro structure between the carburization process and coconut shell charcoal media. In the microstructure of the carburizing process with coconut shell charcoal media, there is no visible carbon content that decomposes on the surface of the steel. This happens because the grain size of the coconut shell charcoal media makes it bigger so that at a temperature of $723^{\circ} \mathrm{C}$ with a holding time of 1 hour of carbon from coconut shell charcoal media undergoes a long process to unravel the surface of the steel.

\section{REFERENCES}

[1] J. H. Duffus, "Heavy metals" a meaningless term", Pure Appl. Chem, vol. 74, no.5, pp.793807, 2002.

[2] V. C. Pigott, "The Development of Metal", The Archaeometallurgy of the Asian old world, vol. 16, pp.73, 1999.

[3] T. E. Graedel, and J. Cao, "Metal spectra as indicators of development", Proceedings of the National Academy of Sciences, vol. 107, no. 49, pp.20905-20910, 2010.

[4] H. C. Mercer, Ancient Carpenters' Tools: Illustrated and Explained, Together with the Implements of the Lumberman, Joiner and Cabinet-Maker, reprint Courier Corporation2013, pp. 271-272, 1928.

[5] M. Jafarzadegan, A. H. Feng, A. Abdollah-Zadeh, T. Saeid, J. Shen, and H. Assadi, "Microstructural characterization in dissimilar friction stir welding between 304 stainless steel and st37 steel", Materials Characterization, vol. 74, pp.28-41, 2012.

[6] A. R. Bahman, and E. Alialhosseini, "Change in hardness, yield strength and UTS of welded joints produced in St37 grade steel", Indian journal of Science and Technology, vol. 3, no.12, pp.1162-1164, 2010.

[7] M. Yazdani, M. R. Toroghinejad, and S. M. Hashemi, "Investigation of microstructure and mechanical properties of St37 steel-Ck60 steel joints by explosive cladding", Journal of Materials Engineering and Performance, vol. 24, no. 10, pp.4032-4043, 2015.

[8] M. M. Solomon, H. Gerengi, T. Kaya, E. Kaya, and S. A. Umoren, "Synergistic inhibition of St 37 steel corrosion in $15 \% \mathrm{H} 2 \mathrm{SO} 4$ solution by chitosan and iodide ion additives", Cellulose, vol. 24, no. 2, pp.931-950, 2017.

[9] R. Bjorhovde, "Development and use of high performance steel", Journal of Constructional Steel Research, vol. 60, no. 3-5, pp.393-400, 2004.

[10] A. R. Khalifeh, A. Dehghan, and E. Hajjari, "Dissimilar joining of AISI 304L/St37 steels by TIG welding process", Acta Metallurgica Sinica (English Letters), vol. 26, no.6, pp.721-727, 2013.

[11] A. R. Khalifeh, A.D. Banaraki, H. D. Manesh, and M. D. Banaraki, "Investigating of the tensile mechanical properties of structural steels at high strain rates", Materials Science and Engineering: A, vol. 712, pp.232-239, 2018.

[12] Sularso and S. Kiyokatsu, Dasar Perencanaan dan Pemilihan Elemen Mesin, Jakarta: PT. Pradnya, 2004.

[13] A. Bardelcik, C. P. Salisbury, S. Winkler, M. A. Wells and M. J. Worswick, "Effect of Cooling Rate on High Stain Rate Properties of Boron Steel," International Journal of 
Impact Engineering, vol. 37, no. 6, pp. 694-702, 2010.

[14] K. Janerka, D. Bartocha, and J. Szajnar, "Quality of carburizers and its influence of carburization" process", Archives of Foundry Engineering, vol. 9, no.3, pp.249-254, 2009.

[15] G.V. Samsonov, Mechanical Properties of the Elements: Handbook of the physicochemical properties of the elements, New York: IFI-Plenum, 1968.

[16] M. D. Sebayang, S. M. Yudo, and C. Silitonga, "Effect of heat treatment On Microstructure of steel AISI 01 Tools", In IOP Conference Series: Materials Science and Engineering, vol. 343, no. 1, pp. 012005, March 2018.

[17] M. D. Sebayang, and A. G. Gultom, Studi Analisa Material Dan Desain Produk Perkakas Tangan, 2017.

[18] T. F. Anderson, "Techniques For The Preservaation Of Three-Dimensional Structure In Preparing Specimens For The Electron Microscope", Transactions of the New York Academy of Sciences, vol. 13, no. 4 Series II, pp.130-134, 1951.

[19] P. E. Stutzman, and J. R. Clifton, "Specimen preparation for scanning electron microscopy", In Proceedings of the international conference on cement microscopy, vol. 21, pp. 10-22, 1999, April.

[20] A. D. Kammers, and S. Daly, "Digital image correlation under scanning electron microscopy: methodology and validation", Experimental Mechanics, vol. 53, no.9, pp.1743-1761, 2013. 